\title{
Utopia and the Favelas of Rio de Janeiro
}

\author{
Curtis L. Carter \\ Marquette University, Milwaukee, USA
}

\begin{abstract}
Utopias from ancient times to the present have come and gone. They remain as a part of literary, philosophical and historical texts and communal practices. Yet this subject has never ceased to inspire contemporary minds as well. My aim in this paper is to consider the communities known as favelas that have formed on the edges of the Brazilian city of Rio de Janeiro as a contemporary form of utopian community. The paper begins with a brief analysis of the concept of utopia. Then follows a discussion of the Favela as an urban utopia as seen from the perspective of Latin American philosopher Enrique Dussel's philosophy of liberation as represented in his book, The Philosophy of Liberation. The remainder of the paper will consider in what sense the Favela settlements can be understood as a form of utopia. Among additional sources for this paper, I will refer to the research on the favelas by such scholars as Janice Perlman and Catalytic Communities. Other sources will include art projects in the favelas, the novel and film City of God made on site, and photographs of Miguel Rio Branco taken in the Favelas. All of these artists' representations reflectactual experiences of life in the Favelas. An underlying question throughout will be the role that art might play in understanding utopias.
\end{abstract}

\section{The Concept of Utopia}

The idea of utopia has many formulations, from the constructs found in Plato's Republic and Sir Thomas Moore's Utopia, to contemporary formulations, as informed by such endeavors as the activities of the Ralahine Center for Utopian Studies at the University of Limerick. Common to such efforts to account for utopiasis their grounding in "social political values, policies, and practices, aimed at bringing about a better world however debated, conflicted or contested” (Griffin \& Moylan, p. 11). Utopias may appear as imagined space or real, as text or virtual reality, and in realized communities small or large in scale.

The driving forces behind utopia include a variety of personal and social needs. Among these are religious, philosophical, ideological concerns but also needs driven by changing socio-political and economic factors. In each form of utopia, hope and the possibility of change are essential components. Perhaps the tenor of utopia that I have in mind for looking at favelas in Rio is best understood as "a social experience in solution" rather than a vision of a well formed ideal social system (Williams, pp. 133-134). Perhaps a passage from Robert Musil's The Man Without Qualities suggesting an analogy between contemporary experimental poetry and utopia is useful to characterize the sense of utopia that exists in the favelas.

What poetry and utopian revolt have in common is that radical actuality, ... that actualization of desire no longer exercised in a liberation to come but demanded here, tumultuously even in the part of it that is death driven.... (Musil, p. 120)

Just as a radical strain of poetry challenges the very limits of artistic possibilities, the utopian impulses in the favelas challenges the limits of conventional social and political realities including utopias.

Curtis L. Carter, Professor of Aesthetics, Department of Philosophy, Marquette University, USA. 
In order to give context to the sense of utopia that I propose to engage in examining the practice of utopia as it applies to life in the favelas of Rio de Janeiro, I will draw in part upon the understanding of utopia as it is articulated in Enrique Dussel's Philosophy of Liberation.

\section{Utopia in the Context of a Philosophy of Liberation}

Briefly how shall we understand the philosophy of liberation? The philosophy of liberation is a product of Latin American philosophers who offer an approach to philosophy in underdeveloped countries as an alternative approach to philosophy as it exists in dominant cultures of the West and the East. Philosophy of liberation, in contrast to the view that philosophy is a criticism of language, "affirms that philosophy is a criticism of oppression and a clarification of the praxis (person to person relationship) of liberation" of the oppressed (Dussel, p. 188). Briefly, "Liberation, [is] the act of the oppressed by which they express or realize themselves....” (Dussel, p. 62). It is focused on the realty of the everyday world. The oppressed in this instance includes the poor, rural and day workers, as well as victims of particular forms of racial and gender-based discrimination."The praxis of liberation is the procreation of a new order, of its new structure, and at the same time of the functions and beings that compose it" (Dussel, p. 48). It is "creative, inventive. Innovative”.

Although Dussel does not offer an explicit definition of utopia, the term appears frequently throughout his text in reference to the state of the peripheral oppressed peoples. Dussel distances his views from Adorno's sense of a future utopia. Rather his utopia is a utopia of the present grounded in the everyday realities of the peripheral peoples, and embracing as its ground a philosophy of hope (Dussel, p. 48). On Dussel's view, proximity, understood as a "non-spatial timelessness "or propinquity, is the ground of responsibility for others, including economic relations. "Proximity is a feast of those who are equal, free, and just, of those who yearn for an order of proximity without counterrevolutions or relapses" (Dussel, p. 21). Proximity is a key notion in the conceptual basis for Dussel's notion of utopia.

Throughout Dussel's references to utopia in the Philosophy of Liberation, utopia is represented as a state of conditions hoped for, and as calling for a new order. Utopia then is a process in the making, but not yet fully achieved. For example, in utopian aesthetics the artist's realization of aesthetic value in producing beautiful works of art offers a model for the laborer's economic and technical efforts in the invention and manufacture of useful products. In the realm of politics and economics utopia calls for achieving justice over antagonistic mediations. Even if utopia may not be fully realizable in history, it can nevertheless serve as a useful guide for our reflections and advancement toward liberation for the oppressed and marginal attempting to better their lives (Dussel, p. 139).

\section{Favelas in Rio de Janeiro}

Favelas initially entered the peripheries of Rio de Janeiro in the 19th century when a group of soldiers returning from battle found themselves homeless and forced to find alternative self-developed dwellings. Initially at least, the favelas developed outside government policy or sanction on the hills on the edges of Rio de Janeiro. They served to provide housing for the poor who were excluded by economic, social, and racial barriers from other parts of the city. Initiation and implementation of the favelas is by self-selection. Movement from the countryside and increased urbanization drew greater numbers who chose, or had no other options for housing and developing community. A contemporary definition of favela would include these elements: 
1. Neighborhoods that emerge from an unmet need for housing.

2. Established and developed without external government regulation.

3. Their original blueprint established and developed organically and by residents themselves.

4. Continuously evolving based on culture, access to resources and jobs (Williamson, Favelas as Affordable Housing).

Janice Perlman's some 40-plus-year study of the favelas in Rio de Janeiro begun in the late 1960s with on-site research in the favelas of Rio de Janeiro, as represented in her books Living on the Edge in Rio de Janeiro (2010) and an earlier work, The Myth of Marginality (1976). These books offer a poignant picture of life in the favelas from the perspective of a sociologist. Even as early as the 1920s the favelas (the other) were perceived as a problem by the city. From the outside, "they were seen as a blight on the urban landscape, menace to the public health, and a threat to urban civility." Still favelas continued to grow with waves of urbanization and the attraction of life in the city. For the most part the dwellings in the favelas occupy land with no legal title. Though recognized by the city as "dwellings for poor people," the city has been slow to provide even basic services such as water, electricity, and trash removal service.

Contrary to the external perceptions of the favelas implied by such pejorative labels as slum, shanty town, ghetto, or lawless hubs of drug related violence, Perlman found them to be of interest as sustainable communities. She found the migrants of the favelas "-rather than being... the most impoverished among the rural people were most often the ...most far sighted capable and courageous members of the communities.”

Perlman reports:

From the beginning I found the favelas visually more interesting and humanly more welcoming than the upper middle class neighborhoods. They could be seen as the precursors to the "new urbanism" with their high density, low rise architecture, featuring facades variously angled to catch a breeze or a view, and shade trees to keep them cool. The building materials were construction site discards and ...recycled materials. They were owner designed, owner built, and owner occupied, and they follow the organic curves of the hillsides rather than a rigid grid pattern. (Perlman, Favela: Four Decades of Living on the Edge in Rio de Janeiro xviii)

A similarly view of life in the favelas, and one offering support for a utopian understanding of the favelas, appears in the work of Catalytic Communities, an organization dedicated to understanding and advancement of life in the favelas of Rio de Janeiro. Catalytic Communities argues for viewing life in the favelas of Rio je Janeiro and elsewhere as a sustainable model based on the qualities inherent in such communities. In the words of Theresa Williamson: "Over the years, our work in Rio favelas has exposed us to a wide range of qualities in these communities that are typically associated with sustainable or resilient communities” (Williamson, Favela as a Sustainable Model).

Comments from a resident of favela Santa Marta offer this perspective on current state of life in the favelas offer this perspective,

Things are changing. Today young people say proudly “my community,” [referring to Santa Marta]. People enjoy living in favelas today. My wife and I say that we are favelados. Even foreigners come to see Santa Marta. Madonna came; politicians from the United States come. This has brought self-esteem to the community. (Skidmore)

\section{Favelas as Seen From the Perspective of the Arts}

Apart from advancing philosophical understanding of utopia and scientific studies of the favelas in Rio de Janeiro, it is also useful to consider favelas from the perspectives of the arts. Opportunities for excluded youth point to the contributions of music and visual arts to utopian life within the favelas. As noted in the Rio Times, 
one young boy recounts how the role model for his life was changed from drug lord to musician as a result of being introduced to music (Tafur). Musical contributions of the favelas of Rio de Janeiro to the popular arts are noteworthy as represented in the music and dance relating to funk carioca. Other stories take note of the creative contributions of the favela residents as key contributors to music and dance competitions and festivals. These contributions of the favelas to the popular arts take on new significance for aesthetics as we are called to reflect on Dussel's suggestion that popular culture is the culture of the oppressed groups. According to Dussel, popular culture "is the one that preserves the best of the third world and is the one whence new alternatives will emerge for future world cultures”.

The visual arts also have a role to play in building community in the favelas. From street art graffiti to organized community projects, the visual arts enliven the environments of the favelas and contribute to the sense of utopian hope. Graffiti street art, for example, on underutilized and often decaying walls offer points of engagement on the streets for younger residents of the favelas. Larger formal projects such as the mural paintings of Dutch artists Haas and Hahn created in the Santa Marta favela represent another approach to enrichment of life in the favelas. Since 2005, Haas and Hahn with the cooperation of favela dwellers have created several large painting projects ranging from smaller mural paintings to "a whole street transformed into a river and a giant square turned into a radiant explosion of color" (City Project). Beginning in 2005 with smaller mural projects, their project grew to efforts to transform the main avenue that ran through the favela Vila Cruzeiro with colorful designs on the houses and structures along the avenue. The project was implemented with the help of local artists and a crew of local youngsters (Haas and Hahn). In short, the presence of the arts invites engagement and fosters the hope for a better life for the people living in the favelas. Their effects are summed up nicely in these words:

Favela painting affects the aesthetic order of how favelas are perceived from within and outside its natural embryonic growth. Colour brings hope. It brings a different understanding of space and its people, inviting others to co-create and co-represent much more constructively and positively life here. It appeals to our senses in a way that we do not reject but embrace these places had the potential for better life. It articulates a different discourse of social change; of engagement, contributing to improve life for favela dwellers. (Imas and Kosmala)

Not surprisingly, given its rich cultural activities of the favelas as raw materials for writers, literary writing is also contributing to the enrichment of life in the favelas. For example, the Literary Festival FLUPP began in the favela Prazeres in 2012 and is launching its fourth international festival in 2016 in Babliônia Capéu Mangeria. One aim of FLUPP has been to support writers living in the favelas and to offer literary arts to the people of the favelas as an enrichment of life. As reported by Julio Ludemir founder of the Literary Festival, "We discovered that there is as much appetite for culture in these areas as there is for phones and televisions" (McLoughlin).

Apart from the roles that the arts play in the internal life of favelas, writers and film makers have contributed significantly to awareness and understanding of life within the favelas. Documentaries such as "Favela as a Sustainable Model," produced by Catalytic Communities, offer a view of community life in the favelas aimed at creating awareness of the positive features of life there.

\section{Challenges to Utopia in the Favelas}

Not all of what takes place in the favelas can be seen as a positive contribution to the utopian spirit of life there. The threat from drug traffic and gang violence, especially since the 1980s, offers a substantial challenge 
to the utopian aims of life in the favela. A picture of this aspect of life in the favelas is graphically framed in the 2003 film Cidad de Deus (City of God), co-directed by Fernando Meirelles and Kátia Lund. Perhaps the artist’s production most responsible for a worldwide perspective on this aspect of life is the favelas is the film. This film is based in part on Meirelles adaption of Paulo Lin's 1997 novel bearing the same title, and in part on real events. Lin grew up in the favela named City of God. The novel and the film both center on a segment of life after the entry of drug lords and crime life beginning in the 1980s, in the favela, City of God.

The movie traces the neighborhood's decline over a decade and a half, from a sun baked shanty-town of earth colored bungalows where the children wile away the days in soccer tames and petty thievery into a shadowy slum teeming with armed adolescent warriors. (Holden)

The cast of City of God included some 200 non-professional youth actors from the favelas. Despite the brutality expressed in the film, it also showed "a surprising amount of tenderness and humor beneath the brutality" (Phipps).The novel and the film can be seen as a call for social change in the life of the favelas. The title, perhaps with obliquity, casts a reference to Augustine's classic City of God, which called for reform in reference to the hope to establish a form of utopia, but on a transcendental level.

When understood from the perspective of a view of favelas as seen from the perspective of drug traffic and violence, the favela communities, may appear as marginal with respect to the city itself and perhaps unlikely candidates for a utopian community. However, there are other aspects central to life in the favelas as we have shown. Contrary to the view that the people in the favelas are marginal in respect to the larger city, Perlman offers the following claim:

The evidence strongly indicates that the favelados are not marginal, but in fact integrated into the society, albeit in a manner detrimental to their own interests. They are not separate from, or on the margins of the system, but are tightly bound into it in a severely asymmetrical form. They contribute their hard work, their high hopes, and their loyalties, but do not benefit from the goods and services of the system. It is my contention that the favela residents are not economically and politically marginal, but are excluded and repressed; that they are not socially and culturally marginal, but stigmatized and excluded from a closed class system. (Perlman, Myth of Marginality: Urban Poverty and Politics in Rio de Janeiro 195)

\section{The Case for the Favela as Utopian Communities}

Given the picture of the favela communities, which have both strengths and challenges as we have seen here, what is the case for offering the favela experience as a form of utopia alongside other forms of utopia? Utopia as it relates to favelas is not a literary utopia such as Sir Thomas Moore's Utopia or Edward Bellamy's Looking Backward, although its vision has been explored in the visual arts including film, video art, and in literary arts including utopian novels. ${ }^{1}$ Nor is it a closed, community such as utopian societies established in the United States during the nineteenth century. For example, the Amana Colonies based on shared religious and economic practices, or New Harmony, a utopian experiment based on the social beliefs of a wealthy British industrialist.

Nor can favela communities be considered dystopias as in certain literary utopias where the emphasis is on a community consisting essentially of negative or undesirable qualities. This perception might well be one ensconced in labels such as slum or shanty town when applied to the favelas, but as we have shown here this is

\footnotetext{
${ }^{1}$ Beatrice Jaguaribe offers an overview of developments on this topic: "Favellas and the Aesthetics of Realism: Representation in Film and Literature,” Journal of Latin American Cultural Studies, Vol. 13, no. 3, December 2004, pp. 327-342.
} 
not the core essence of life in the favelas. In fact, the qualities often cited for dystopias, for the most part do not apply to favelas. For example, the type of social control operative in the favelas is not corporate, bureaucratic, technological, nor philosophical. Favelas are not futuristic fantasies; rather they exist as real life realities in which people strive to build a better life. There is no restriction to independent thought, as the favela residents' have literally built their communities including housing and services for the most part over more than a century of independent existence. Similarly, the favela residents do not fear the outside world; rather they exist for the most part as a challenge to or in defiance of the wider city of Rio de Janeiro. And they do not conform to uniform expectations of the external world, although they welcome the interest and participation of visitors. ${ }^{2}$ Further, the people of the favelas do not envision their society as an illusion of a perfect utopian world.In this respect, they share with dystopia certain qualities. At least some of the residents have existed, in or continue to exist, in a dehumanized state denied the normal humanitarian support from the external city, and infested with drug lord crime and violence including police violence.

These imperfections in the utopia of the favelas, do not as such warrant a concession to Karl Popper's fear that utopia requires eliminating opposing viewsor necessarily surrendering to temporary states of violence (Popper). It is unfortunate that the unpredictability of human behavior can lead to undesirable consequences as has been evident in both literary and actual utopian communities. This is true whether the foundations of the utopia are philosophical, religious, political, economic, or as it is with the favelas, a need for self-liberation in pursuit of a better life and a better world.

Recall that the success of the favela communities has evolved out of a real life struggle for self-liberation. Looking at the progress that the favelas have made in their century plus history, there is reason to hope that the communities will be able to overcome the blight of crime and violence that has temporarily eclipsed some of the fine community development within the favelas. Among these are success in creating community social space as a place with emotional, cultural, and practical resonance while coping with the existential dimensions of everyday life which includes jobs, shelter, food and a lively arts culture (Dussel, p. 18). In the words of a resident of favela Santa Marta, "Things are changing. Today young people say proudly, 'my community.' People enjoy living in favelas today. My wife and I say that we are favelados with pride” (Skidmore).

The central idea of utopia is grounded in an experience of hope and actions aimed toward the betterment of life. The key notion when considering the favela as utopia is the idea that the favela serves the purpose of meeting the needs of a disenfranchised segment of the people. The favelas dweller shave succeeded in sustaining communal efforts toward liberation for over a century. Hence the pursuit of utopia in the favelas has lasted longer than most if not all previous attempts to form a utopian community. From its beginnings as an effort to accommodate a basic need for shelter, the favelas have struggled to attain access to the services accorded to other citizens of the surrounding city. In doing so, as the reports of Perlman and others show, favelas have developed a sustainable community based on the hope of the betterment of life.

Philosophical support for the claim that the favelas offer a form of utopian community for its disenfranchised residents is offered in Dussel's philosophy of liberation, as was noted earlier. Additional insight into the form of utopia that is found in the favelas is a comment of philosopher Robert Nozick:

There will not be one kind of community existing and one kind of life led in utopia. Utopia will consist of utopias, of many different and divergent communities in which people lead different kinds of lives... Utopia is a place where people

2 These are qualities offered as characteristics of dystopian communities. 
are at liberty to join together voluntarily to pursue an attempt to realize their own vision of the good life...but where no one can impose his own utopian vision upon others. (Nozick, p. 311)

The view of utopia found in the favelas is also compatible with the account of utopia offered by sociologist Ruth Levitas and published in The Concept of Utopia (1990) and in Utopia as Method: The Imaginary Reconstruction of Society (2013). Her view lends further support to a utopian reading of life in the favelas. In Levitas' words, "Utopia is the expression of the desire for a better way of being... It allows for the desire to be realistic or unrealistic. It allows for the form, function, and content to change over time” (Levitas, p. 9). Levitas' understanding of utopia thus avoids the claims of universality or determinative connection of utopia to social change. Rather the realization of utopian aims rests on the desire and willful actions of the community toward realization of a better life and a better world.

\section{Conclusion}

In the context of a philosophy of liberation there are numerous questions relating to utopia: what is the role of utopia? Is it a temporary transitional stage, or an ongoing means of resistance to injustice in an unhealthy state of the larger social order? Is its role to liberate oppressed people in the service of justice? Is it a temporary stage in the evolution of a just society? Remedial and transitional? Is its aim to serve as a model for transformation of the larger social order? As a beginning response to these broader questions concerning utopia, already beyond the scope of our task in this essay, we have offered the experience of the favela formed around the edges of the city of Rio de Janeiro. Utopia as it is forged in the favelas is constructed out of real social needs arising in the lived condition of the people who migrate there and desire to build a better life. A better life includes justice alongside aesthetic and economic components among others. To its residents, the favela represents a way of life, a state of mind. Among the strengths necessary to build a utopian community are human skills and capacities. Among these are trust, solidarity, and reciprocity. These qualities, augmented by inventiveness in solving the needs of daily life in an environment that frequently poses challenges, are resilient in the people of the favelas. Seen in this light, life in the favelas thus offers possibilities for a life style that is in spirit, and in achievement utopian. That is, it is a life grounded in proximity and hope aimed at bringing about betterment of the world.

\section{References}

Dussel, E. (1985). Philosophy of liberation, English translation. Mary Knoll: Orbis Books.

“Favela Painting Project”. City Project, May 2015. Retrieved from http://www.cityproject.it/favela-painting-project/

Griffin, J. M., \& Moylan, T. (2007). Introduction: Exploring Utopia. In J. G. Michael and T. Moylan (Eds.), Exploring the Utopian impulse: Essays on Utopian thought and practice (p. 11). Bern: Peter Lang AG.

Haas \& Hahn (2015). Back to Rio. Favela painting project. Retrieved from www.favelapainting.com

Holden, S. (2003). Film review: Boys soldiering in an army of crime. New York Times, 17 Jan. 2003.

Imas, J. M., \& Kosmala, K. (2010). Dr. J. M. Imas and K. Kosmala after visiting the Dona Marta project wrote us the following $\begin{array}{llllll}\text { letter. } & \text { Facebook, } & 7 & \text { May } & 2010 . & \text { Retrieved }\end{array}$ https://www.facebook.com/notes/favela-painting/dr-j-m-imas-and-k-kosmala-after-visiting-the-dona-marta-project-wrote-usthe-fol/125745827436274

Levitas, R. (1990). The concept of Utopia. London: Alan.

McLoughlin, B. (2012). Rio de Janero Festival brings literature to favelas. BBC News, 23 April 2012. Retrieved from http://www.bbc.com/news/world-latin-america-17692984

Musil, R. (1995). The man without qualities. Trans. Sophie Wilkins. London: Picador.

Nozick, R. (1974). Anarchy, state, and Utopia. New York: Best Books. 
Perlman, J. (2011). Favela: Four decades of living on the edge in Rio de Janeiro. New York: Oxford University Press.

Perlman, J. (1980). Myth of marginality: Urban poverty and politics in Rio de Janeiro. Berkely: University of California Press.

Phipps, K. (2003). City of God: Movie review. AV Club, 27 Jan. 2003. Retrieved from http://www.avclub.com/review/city-of-god-5792

Popper, K. R. (1986). Utopia and Violence. World Affairs 149.1(1986), 3-9.

Raymond, W. (1997). Marxism and literature. Oxford: Oxford University Press.

Skidmore, T. E. (2009). Brazil: Five centuries of change. New York: Oxford University Press.

Tafur, J. (2009). Favela Music Changes Lives. Rio Times, 18 August 2009.

Williamson, T. (n.d.). Favela as a Sustainable Model. Catalytic Communities. Retrieved from http://catcomm.org/favela-modelo/

Williamson, T. (n.d.). Favelas as Affordable Housing. Catalytic Communities, 16 May 2013. Retrieved from http:/catcomm.org/vision/ 